\title{
Geochemical Evidence for Palaeo-Environments of Algal Mats and Peat in Sri Lanka
}

\author{
C. B. DISSANAYAKE, A. SENARATNE, S. V. R. WEERASOORIYA \\ Department of Geology, University of Peradeniya, Peradeniya, Sri Lanka \\ AND \\ G. P. WANNIGAMA \\ Department of Chemistry, University of Peradeniya, Peradeniya, Sri Lanka.
}

(Date of receipt : 18 October 1983)

(Date of acceptance : 20 January 1984)

\begin{abstract}
V/Mn ratios with the organic carbon content and a C-29 sterol compound indicative of higher plants in a terrestrial environment have been used to demarcate the different palaeo-environments of algal mats and peat deposits of Sri Lanka. These chemical parameters were found to be especially useful in the delineation of marine, tidal-flat, lagoonal and terrestrial environments of deposition.
\end{abstract}

\section{Introduction}

Algal mats and peat are now being studied for their metal distributions as they may provide useful clues to the formation of certain metal-bearing mineral deposits, even during Precambrian times. ${ }^{1,15}, 16$ The classic work of Renfro ${ }^{15}$ on the genesis of evaporite associated stratiform metalliferous deposits in sabkha environments laid the foundation for further research. Both algal mats and peat, being organic materials, are the subject of studies on metal trapping properties by naturally occurring organic matter: ${ }^{2}, 5,7,13,14,17$

A fundamental necessity in all these studies is the reconstruction of the palaeoenvironment of the deposits and the conditions of deposition. It is the aim of this paper to make use of certain inorganic and organic constituents of the deposits to trace the source materials and the environments of deposition using two such deposits from Sri Lanka.

\section{The Muthurajawela peat deposit}

The Muthurajawela peat deposit(Figure 1) is the largest in Sri Lanka, but up to the present, this deposit has not been utilized. The area studied consists of flat land perennially in a water-logged condition with the depth of water varying from place to place. Specialized vegetation characterized by brackish water plants is prevalent. The swamp area representing the southern extension of the Negombo lagoon, is bounded 

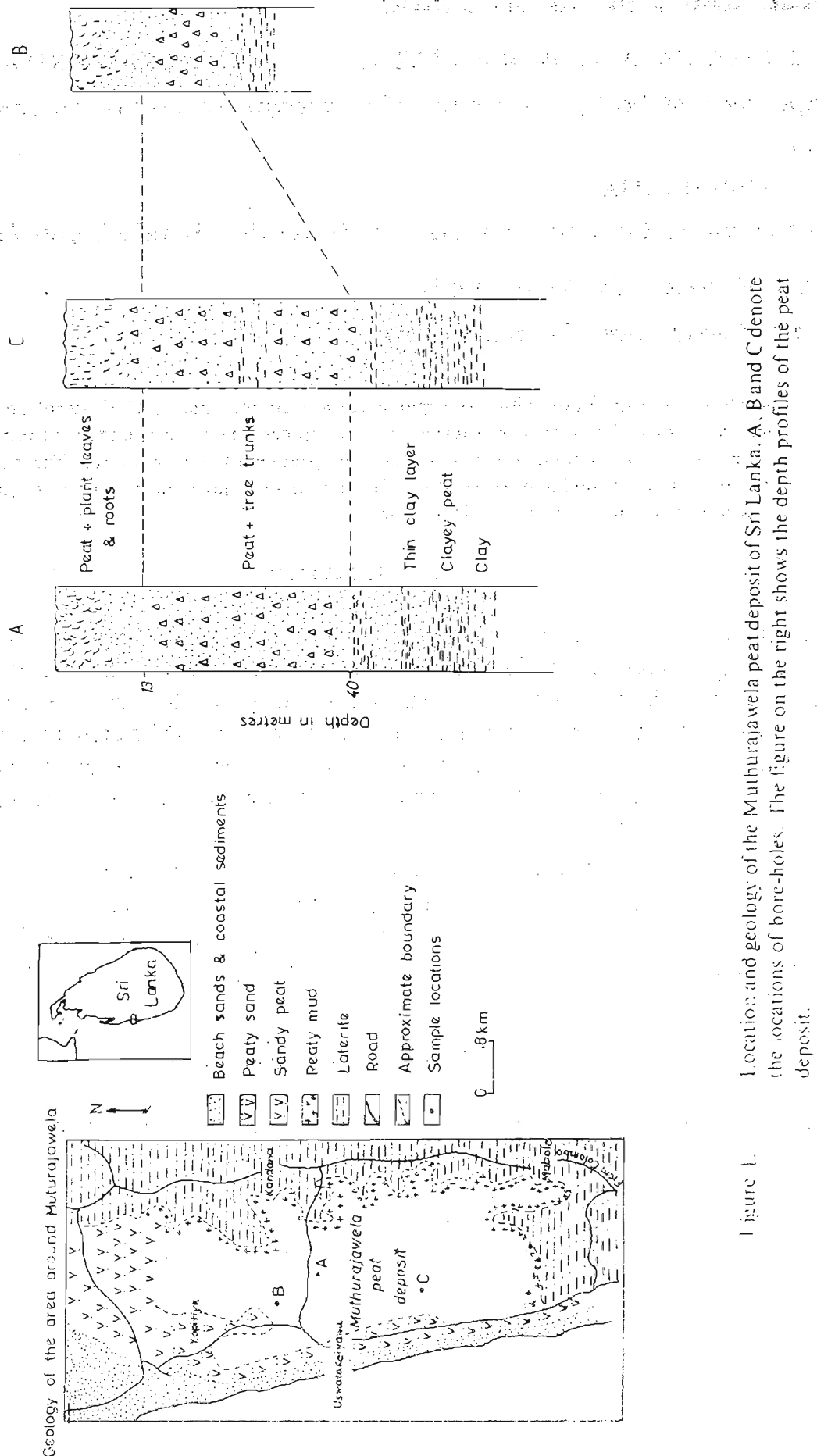
on the east by a belt of laterite (Figure 1) and on the south by a succession of laterite, peaty sand, and coastal sediments. Northward it is bounded by sandy peat and peaty sand: The peat deposit covers an area of approximately $21 \mathrm{~km}^{2}$; the average thickness being $3.7 \mathrm{~m}$. The maximum thickness is in excess ${ }^{3}$ of $5 \mathrm{~m}$.

Along the sea coast on the western side of the swamp, a beach sand belt containing heavy minerals occurs. There are no sharp contacts a mong the lithological variations, sand, peaty sand, and sandy peat passing gradually into each other. On the eastern side, peat is mixed with lateritic mud, and no obvious boundary exists. These intermediate areas are covered by paddy fields.

\section{The algal mats of Mannar}

These algal mats are located in the Mannar Island tidal flats off the northwest coast of Sri Lanka(Figure 2).'They are laminated blue-green algal mats forming in the intertidal zone of a clastic (non-carbonate) tropical and lagoonal tidal flat. Gunatilaka6 studied these algal mats in detail and recognized three different types namely:

(a) a smooth rounded-mat zone with discrete structures,

(b) a crinkled and blistered zone,

(c) a smooth flat-mat zone without any perceptible relief.

The mats were formed by the trapping and binding of sediment particles on to a sticky mucilaginous complex of algal filaments. All three zones are characterized by laminations produced by the alternation of thick sediment with thin algal-rich layers and show an accretion rate of $5-15 \mathrm{~mm} /$ week. For a detailed account on the biology and sedimentology of the present-day Mannar algal mats, the reader is referred to Gunatilaka6

\section{Material and methods}

Peat samples from three bore-holes A, B and C (figure 1) were taken at various depths and air-dried. Each air-dried sample was crushed, ground and the minus $63 \mu \mathrm{m}$ fraction retained for analysis.

Approximately $0.5 \mathrm{~g}$ of the sample was weighed in a teflon crucible and heated for 20-25 minutes with $15 \mathrm{ml}$ conc $\mathrm{H}_{2} \mathrm{SO}_{4}$ until the organic matter was thoroughly decomposed. A $70 \%$ mixture of conc $\mathrm{HNO}_{3}$ and conc $\mathrm{HCl}$ were then added and carefully heated to dryness. $20 \mathrm{ml}$ of $60 \% \mathrm{HF}$ was added to the residue to dissolve any silica present. The final solution was then taken up in $25 \mathrm{ml}$ of $3 \mathrm{~N} \mathrm{HCl}$. The $\mathrm{V}$ and $\mathrm{Mn}$ contents were determined by Inductively Coupled Spectrometry (ICP) using a Bausch - Lomb ARI instrument. 
The organic contents of the samples were determined by the pyrolysis and method of difference technique. The $\beta$-sitosterol contents of the peat samples were determined by ethyl acetate extraction and preparative thin layer chromatography (TLC).

The algal mat samples were collected from the inter-tidal zone and analyzed by the same procedure as mentioned above.
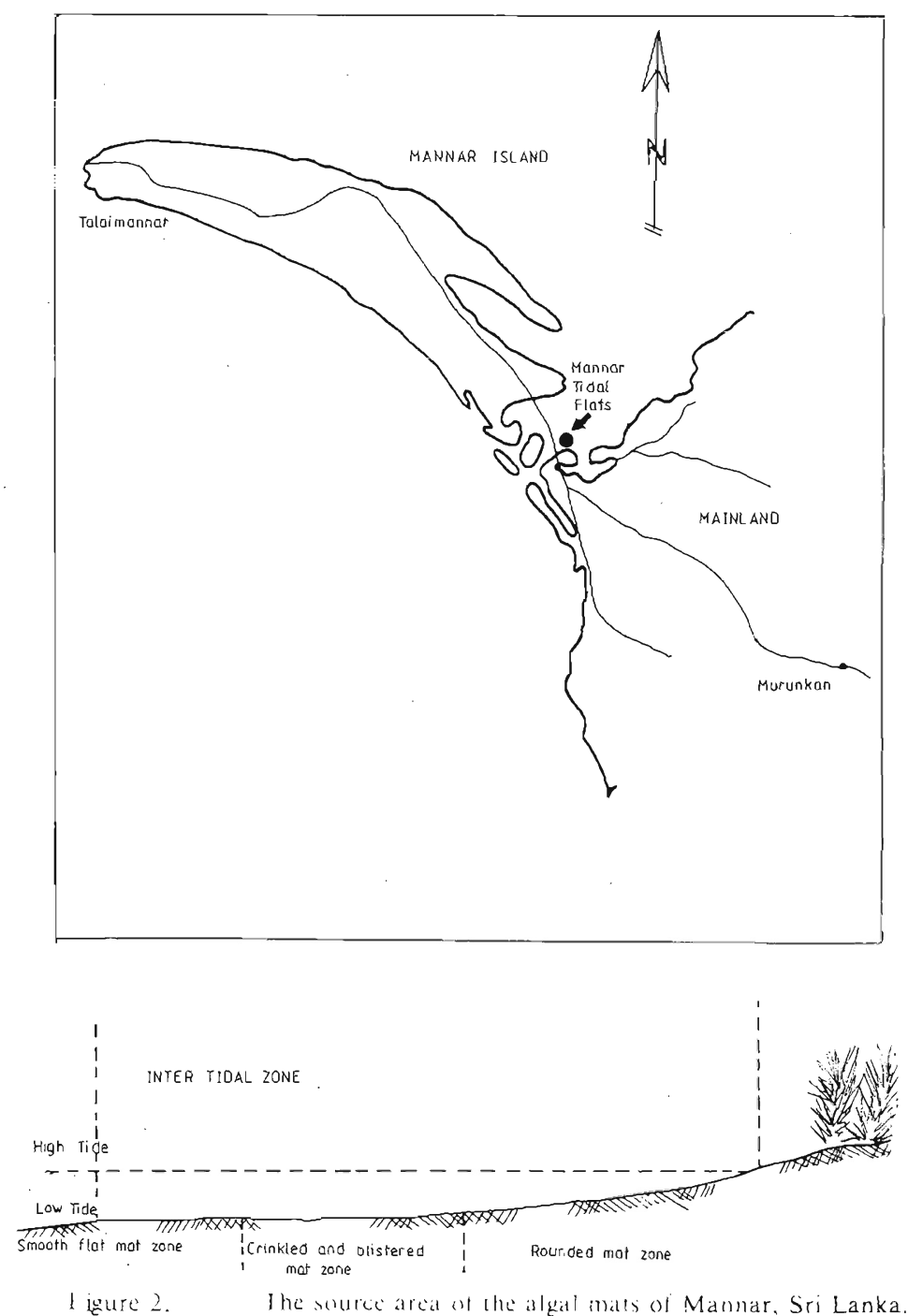


\section{Results and discussion}

Table 1 shows the analytical data obtained. In order to identify the nature of the source materials in the peat deposit, the compound $\beta$-sitosterol was used. In recent advances in organic geochemistry certain specific compounds have been used as environmental markers. As an example, the sterols are widely distributed as distinctive constituents of oceanic and terrestrial plants. The presence of branched side chains and asymmetric centres in the polycyclic sterol skeleton have allowed the development of a high specificity of certain sterols to certain types of plants! ${ }^{12}$

The qualitative differences in the sterol contents of sediments depend on the diversity of floral population and hence on the environmental and biological sources. Huang and Meinschein ${ }^{10}$ have observed a relationship between C-27, C-28, C-29 sterol composition and the depositional environments (Figure 3). It is of interest to note that vascular plants, the primary producers of terrestrial organic matter, have a tendency to synthesize $\beta$-sitosterol (a C-29 sterol) as the major sterol! ${ }^{2}$

It has been established that although $10^{12}$ combinations of structural and optical isomers of C-27 to C-29 alcohols are theoretically possible, less than 10 distinctively structured C-27 to C-29 sterols comprise more than $90 \%$ by weight of biological sterols. It is the highly restricted number of structures which make it possible to use sterol analyses in ecological and environmental investigations.9.11 These observations serve as guidelines in this study to evaluate the different environments that prevailed during the deposition of the Muthurajawela peat deposit.

Figure 3 illustrates the concentration of $\beta$-sitosterol as a function of depth for the locations $\mathrm{A}, \mathrm{B}$ and $\mathrm{C}$. The concentration of $\beta$-sitosterol is highest in the middle horizon whereas in the top and bottom horizons, its content is lower. It is clear that the anomalous increase in the sterol concentration coincides with the less decomposed tree trunk debris in the middle horizon. This indicates that the middle horizon is of an origin different to the top and bottom horizons.

Figure 4 illustrates the variations in sitosterol concentration in the sample versus $\mathrm{V} / \mathrm{Mn}$ ratios. The latter ratio was chosen in view of the fact that the $\mathrm{V}$ content could be used to distinguish between terrestrial and non-terrestrial sources, $V$ being more abundant in marine materials. From Figure 4 it is seen that the depositional environments for the top, middle and the bottom horizons of the peat deposit can be distinguished.

The negative correlation observed for the middle horizon is clearly a feature caused by abundant terrestrial input and a corresponding increase in the $\beta$-sitosterol content. With the increasing influx of terrestrial material there is a corresponding lowering of the $\mathrm{V} / \mathrm{Mn}$ ratio due to the lower $\mathrm{V}$ contents of the terrestrial materials. A further point of interest is the higher gradient of the point clusters observed for the bottom horizon when compared to that of the top horizon. It appears that the bottom horizon constitutes partly terrestrial and partly marine source materials. 
Table 1.- Analytical data for the peat arid algal mat samples from Sri Lanka.

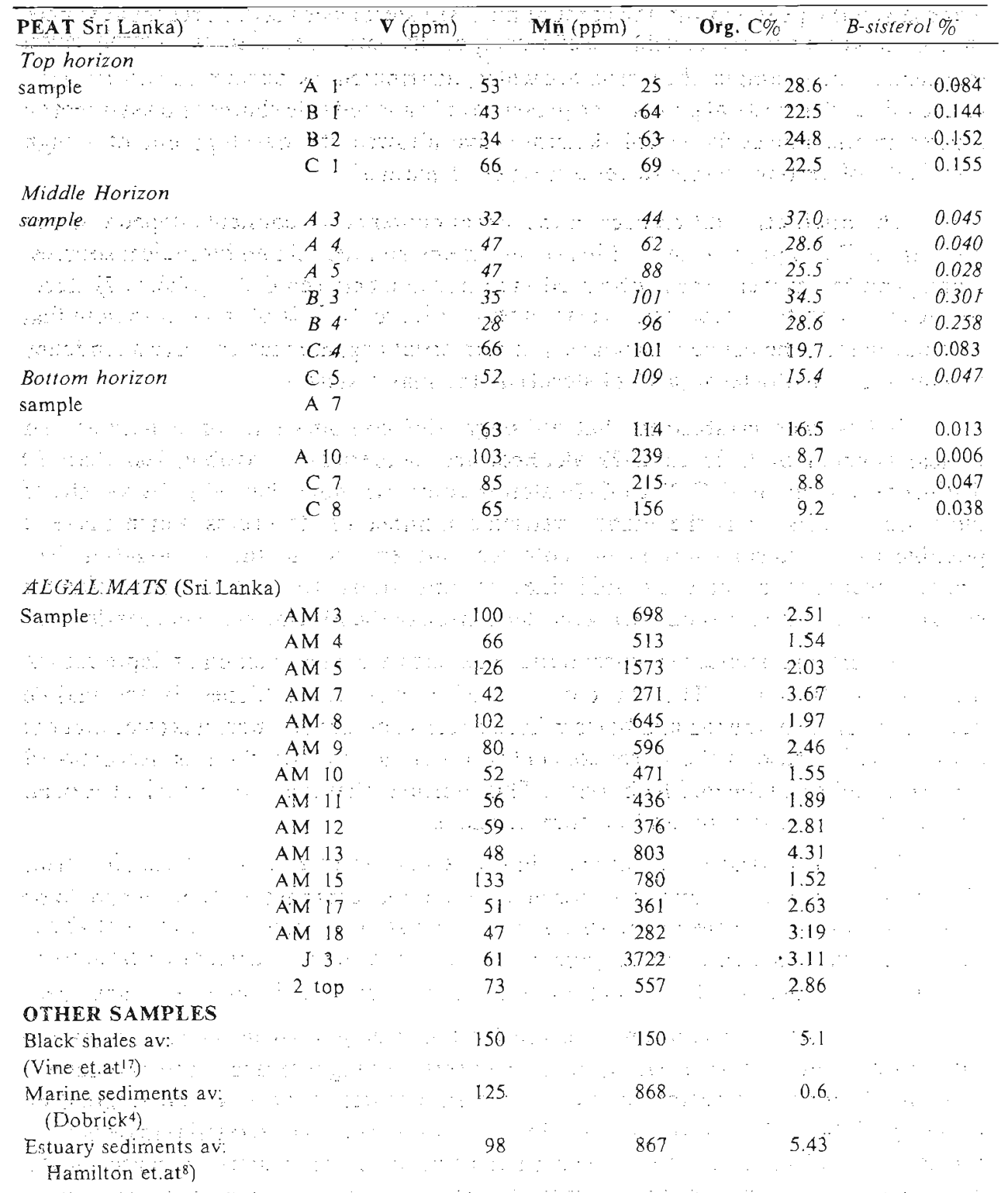




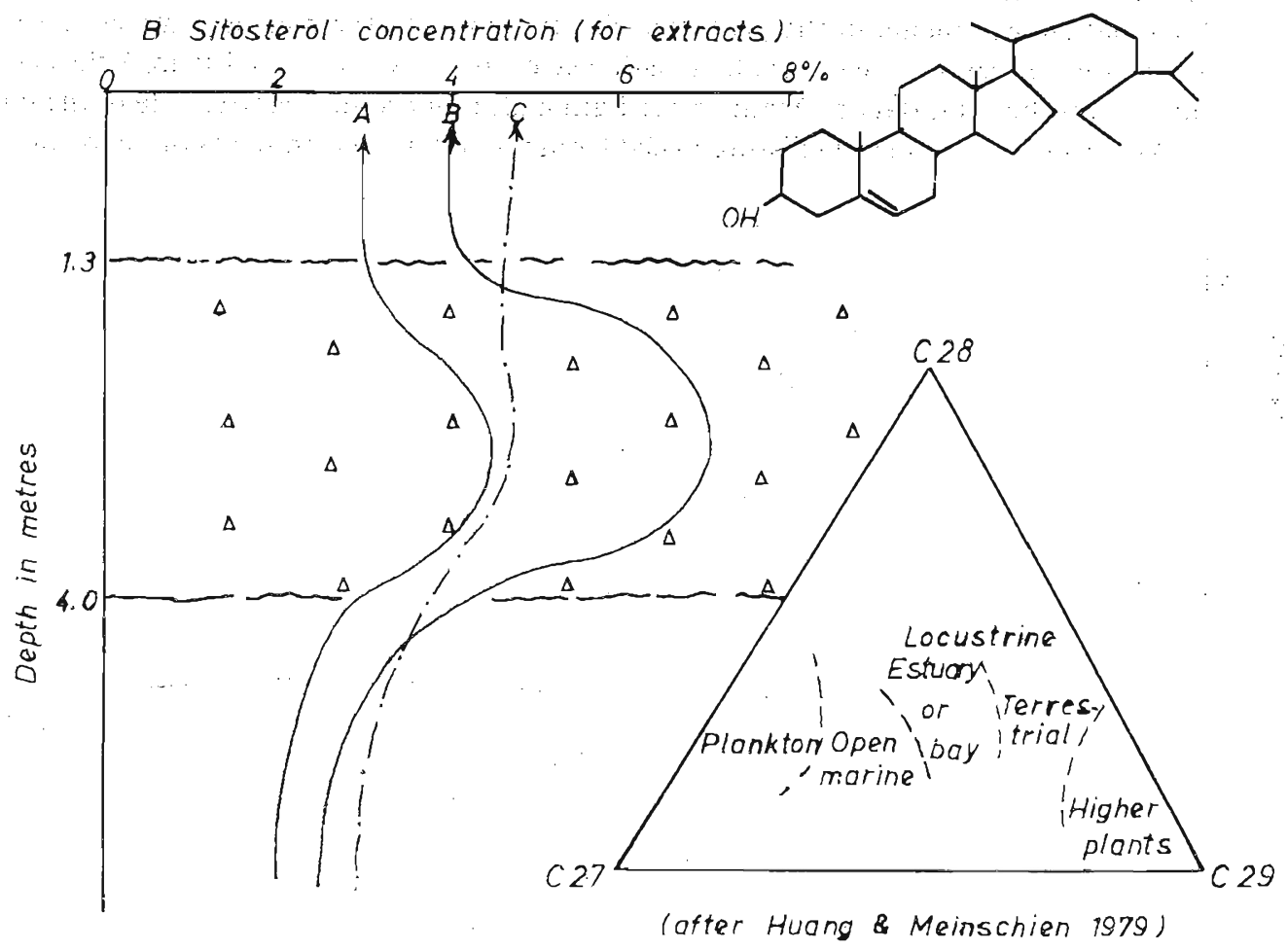

ligure 3. Variation of B-sitosterol concentration as a function of depth in the peat deposit of Sri Lanka. 
The use of $\mathrm{V} / \mathrm{Mn}$ ratios to delineate terrestrial and marine/semi-marine cnviromments can be illustrated further in. Figure 5. The different environments namely (a) geosynclinal (b) tidal flat (c) lagoonal (d) terrestrial - the top, middle and the bottom horizons of the peat deposit. (e) marine are demarcated.

The top. middle and bottom horizons of the peat deposit of Sri Lanka are again clearly distinguished and it is worthy of note that the more marine based samples of the lagoonal environments in the peat deposit plot closer to the marine samples. These samples were also observed to contain marine pelecypods. As shown in Figure 5. the algal mats from the tidal flats of Mannar. Sri Lanka all plot on the negative side of the log $\mathrm{V} / \mathrm{Mn}$ scale and are clearly distinguished from the other environments of deposition.

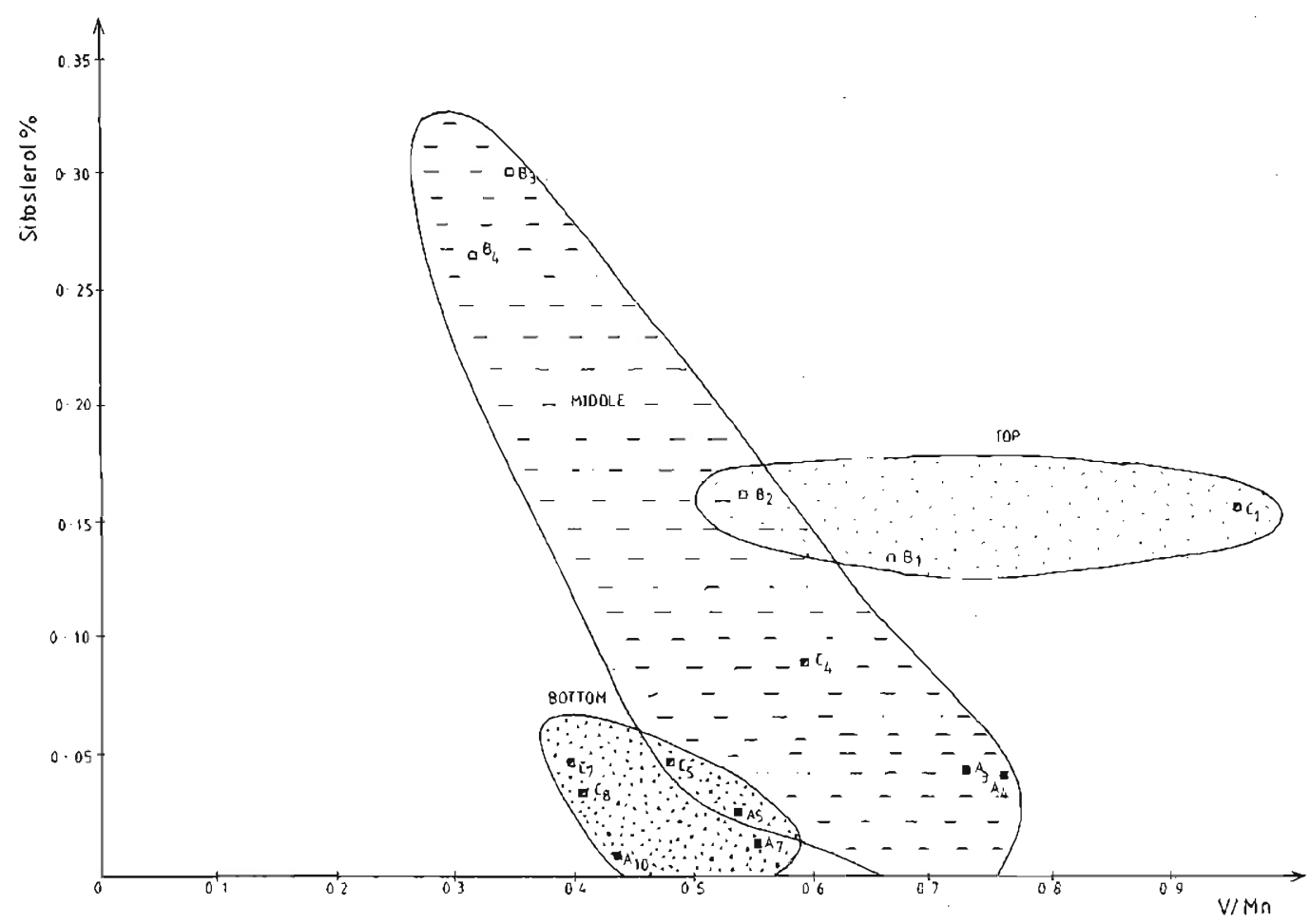

ligure 4. Plots of sitosterol concentration with V: Mn ratios for the top. middle and bottom horizons of the neat deposit of Sri lanka 
Gershemical Evidence for Palaeo-Environments of Algal Mats and Peat in Sri Lanka 245 $\log V / M n$

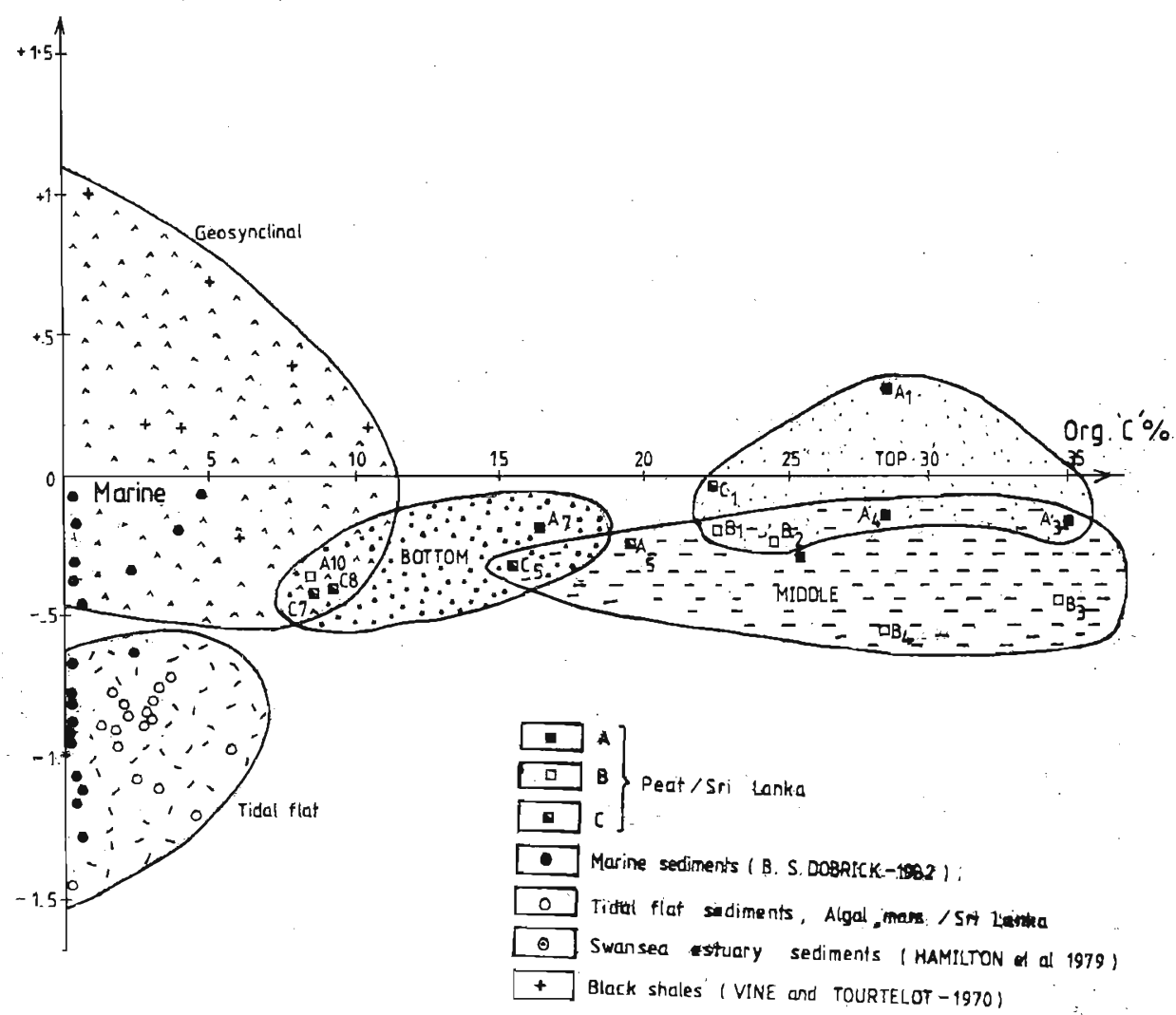

Iigurc 5. Plots of $\log \mathrm{V} / \mathrm{Mn}$ with the organic carbon C; for the three horizons of the peat deposit of Sri Lanka and for other samples from different environments.

\section{Acknowledgements}

Thanks are due to Mrs. J. Rarraweera and Mr. S. M. B. Amunugama for their assistance.

\section{References}

1. BAULD. J.. (1981). B.M.R. Journal of Australian Geology and Geophisics 6:307-317

2. BUBELA. B.(1980). B.M.R. Journal of Australian Geolog! and Geoph!riks: 5:257-263.

3. Dissanayake. C. B.. Senaratne. A. \& Gunatilaka. A. A. L. (1982). Organic Geochemis/1 4 : 19-26. 
4. DOBRICK, B. S. (1982). Senckenbergiana Lethaea 63:161-170.

5. FERGUSON, J. \& BUBELA, B. (1974). Chemical Geology 13:163-186.

6. GUNATILAKA, A.,(1975). Sedimentary Geology 14:275-300

1 7. HAllberG, R. O., BUBELA, B \& FERGUSON. J. (1980). Geomicrobiology Journal 2:99-113.

8. HAMILTON, E. I., WATSON, P. G., CLEARY, J. J. \& CLIFTON. R. J. (1979). Marine Geology 31 : $159-182$.

9. HUANG, W. Y., \& MEINSCHEIN, W. G. (1976). Geochim. Cosmochim. Acia 40:323-330.

10. HUANG,W. Y. \& MEINSCHEIN, W. G. (1979). Geochim. Cosmochin. Acia 43:739-745.

11. JOHNS, R. B., VOlKMAN, J. K. \& Gillian, F. T. (1978). Am. Pet. Expl. Ass, J. 15:157-160.

12. LEE, C., FARRINGTON, J. W. \& GAGOSIAN. R. B. (1979). Geochim. Cosmochim, Acta $43: 35-46$.

13. RADTKE A. S. \& SCHEINER. B. J. (1970). Economic Geology 65:87-101.

14. RASHID, M. A. (1975). Bedford Institute of Oceanographi:, Ocean Science Reviews. 3:43-51,

15. RENFRO, A. R. (1974). Economic Geology 69:33-45.

16. SKYRING, G. W. \& JOHNS. I. A. (1980). Micron 11:407-408.

17. VINE, J. D. \& TOURTELOT, E. B. (1970). Economic Geology 65:253-272. 